\title{
Sense of Defeat, Social Status and Oral Health among Forensic Psychiatric Patients
}

\author{
Abraham P. Buunk \\ Prof. Dr., University of Groningen, Groningen, The Netherlands \\ Yvonne A.B. Buunk-Werkhoven \\ PhD, SPOH ARTS - International Oral Health Psychology, \\ Amsterdam, The Netherlands
}

\section{Abstract}

Aims: The aim was to examine how sense of defeat and social status are related to perceived oral health, tooth brushing, and oral health-related quality of life among Dutch male forensic psychiatric patients.Methods: The sample consisted of 40 hospitalized forensic psychiatric patients participated. The questionnaire included five questions about moments of tooth brushing, scales for sense of defeat and subjective social status, a scale from 1 to 10 for perceived oral health and a Dutch version of the Oral Health Impact Profile14 (OHIP-14).Results: The results showed that on the basis of a factor analysis of the OHIP-14, three meaningful scales could be constructed, i.e., functional limitations, social discomfort, and psychological inhibitions. The major results revealed that sense of defeat correlated negatively with tooth brushing after breakfast and before going to sleep, positively with social discomfort because of one's teeth, mouth, or dentures, not with functional limitations, and negatively with self-perceived oral health. Social status correlated positively with tooth brushing before going to sleep, with psychological inhibitions, but not with social discomfort, and neither with functional limitations.Conclusions and implications: The major conclusion is that sense of defeat and social status have theoretically meaningful relations with oral self-care and oral health. Oral health professionals working with male forensic psychiatric patients should be sensitive to the sense of defeat these patients may experience, and to the fact that this may be associated with problems with their oral health and with a lack of oral self-care.

Keywords: Defeat, Social Status, Oral Health, Forensic psychiatric patients, oral health-related quality of life 


\section{Introduction}

According to the theory of involuntary subordinate strategies, as in many other social animals, humans compete with each other for status and prestige in groups. Status can be based on power and dominance, but also on what has been referred to as social attention holding potential (Allan \& Gilbert, 1995; Buunk \& Brenninkmeyer, 2000), the ways in which one can attract attention and appreciation from others. More specifically, the sense of subjective status or subjective rank includes a perception of how well one is doing in comparison to others with respect to one's strength and power (i.e., the ability to win conflicts and meet challenges), one's social attractiveness and talent (i.e., the ability to be chosen by others for a team, as a friend or lover), and the extent to which one 'fits in the group'. In the evolution of status in human groups, humans became less oriented towards attaining physical dominance, but more towards attaining a sense of symbolic dominance (Barkow, 1989; Buunk \& Ybema, 1997). A low subjective status is associated with a low well-being, and becomes particularly problematic -and can involve important mundane costs for oneself and one's familywhen no escape is felt to be possible. According to the theory of involuntary subordinate strategies, such blocked escape may induce a sense of defeat, and may bring individuals in a 'giving up' state of mind (Gilbert \& Allan, 1998; Buunk, Peíró, Rodríguez, \& Bravo, 2007), feeling like a loser, feeling unsuccessful and having low self-confidence.

A sense of defeat seems an especially a salient issue among criminal offenders, and will be particularly relevant for males (cf. Cummins, 2007). From an early age, males engage more than females in physical and non-physical forms of competition than females (Campbell, 2002). Indeed, a study in Spain showed that a sense of defeat was related to a low life satisfaction among young male, but not among young female criminal offenders (Buunk, Peiró, Rocabert, \& Dijkstra, 2016).

The aim of the present pilot study was to examine how among male forensic psychiatric patients subjective social status and sense of defeat were related to moments of tooth brushing, perceived oral health, and oral health-related quality of life (OH-QoL) (Werkhoven, Spreen, Buunk, \& Schaub, 2004). Insight in factors associated with oral self-care practices is of great importance for developing oral health care interventions (Buunk-Werkhoven, Dijkstra, \& van der Schans, 2011a; Buunk-Werkhoven, Dijkstra, van der Wal, Basic, Loomans, van der Schans, \& van der Meer, 2009a). Oral health is considered as a multi-faceted phenomenon, including the ability to speak, smile, smell, taste, touch, chew, and swallow, as well as the ability to express a range of emotions through facial expressions with confidence and without pain, discomfort and disease of the craniofacial complex. Oral health is influenced by the individual's perceptions, expectations and ability to adapt to circumstances (Buunk-Werkhoven et al., 2011a; Glick, Williams, Kleinman, Vujicic, Watt, \& Weyant, 2016). 
To assess oral health, the short form of the Oral Health Impact Profile (OHIP) (Locker, 1988) is, as its Dutch version, the OHIP-14-NL (Buunk-Werkhoven, Dijkstra, \& van der Schans, 2009b; Buunk-Werkhoven, Dijkstra, Schaub, van der Schans, \& Spreen, 2010; Buunk-Werkhoven, Verheggen-Udding, \& van den Heuvel, 2011b), a self-report instrument aimed at measuring the negative social, psychological, and physical consequences of oral health problems: the more frequent such problems, the lower the OH-QoL. It was expected thatthese aspects of oral health would be lower among forensic patients who experienced a low status, and especially a sense of defeat, as their 'giving up' state of mind would make them less motivated to engage in oral health self-care.

\section{Research Methods}

Ethical clearance and permission for this study was obtained from the ethical committee of the forensic psychiatric hospital Dr. S. van Mesdag in Groningen, The Netherlands. The study was conducted in accordance with the Declaration of Helsinki; an extensive formal written informed consent was obtained from all the participants. A total of 40 male forensic psychiatric patients participated in this study; the mean age of the participants was 33.70 ( $S D=6.40$ ), with a range of 23 to 49 years. They constituted a random sample of the patients of the hospital, including patients with psychotic vulnerability (40\%) and patients with personality disorders (60\%) (BuunkWerkhoven et.al., 2011a; Buunk-Werkhoven et al., 2010; Buunk-Werkhoven et al., 2011b).After providing the written informed consent, participants answered voluntarily a paper-and-pencil-questionnaire, which was based on previously validated scales.

\subsection{Measures}

Oral self-care. Because of the nature of the present sample, five simple questions were asked about moments of tooth brushing, i.e., 'Do you brush your teeth before breakfast?', 'Do you brush your teeth after breakfast', 'Do you brush your teeth in the afternoon?', 'Do you brush your teeth after evening dinner', and 'Do you brush your teeth before going to sleep?'. These questions were taken from the widely used Dutch index for OHB (Buunk-Werkhoven et al., 2009a; Buunk-Werkhoven et al., 2011a; Brein,Fleenor, Jr., Kim, \& Krupat, 2015; Patel, Kulkarni, Doshi, Reddy, Reddy, \& BuunkWerkhoven, in press), and were analyzed separately.

Self-perceived oral health. Participants were asked to indicate on the Cantril ladder (Cantril, 1965) how they valued their own oral health, on a scale from 1 to 10 (i.e., $1=$ poor, $5=$ not poor $/$ not excellent, 10 = excellent) (Buunk-Werkhoven et al., 2009a).

Oral health-related quality of life. To assess OH-QoL (Locker, 1988) a slightly adapted Dutch version of the widely used Oral Health Impact Profile-14 (OHIP-14) (Werkhoven, et al., 2004) was used. This OHIP-instrument consists of 14 items organized -the original order was shuffled-in seven dimensions of each two items, i.e., function limitation (Q4-Q14), physical pain (Q2-Q5), psychological discomfort 
(Q1-Q9), physical disability (Q12-Q10), psychological disability (Q13-Q8), social disability (Q7-Q3), and handicap (Q11-Q6). Responses were scored on a five-point Likert scale (i.e., $0=$ never, 1 = sometimes, 2 = regularly, $3=$ often, $4=$ very often) (Werkhoven et al., 2004; Buunk-Werkhoven et al., 2010; Buunk-Werkhoven et al., 2011b). However, because the original OHIP-14 (Locker, 1988) consists of seven subscales of each two items, which is from a psychometric perspective not satisfactory, it was decided to examine if there were a few theoretically and practically meaningful dimensions underlying the scale, and if on this basis reliable scales could be constructed. For this purpose, first, a factor analysis on the present version of OHIP-14 was conducted.

Subjective status. This variable was measured with the Social Comparison Scale (Allan \& Gilbert, 1995; Buunk \& Brenninkmeyer, 2000); this scale consists of 11 bipolar constructs based upon semantic differential methodology. Participants were asked to complete the sentence 'In relationship with others I generally feel .....'. The scale includes constructs such as inferior-superior, incompetent-competent, different-same, untalented-talented, and unattractive-attractive. The reliability of the scale used in the present sample was high, Cronbach's alpha $=0.87$.

Sense of defeat. This variable was measured with the validated Sense of Defeat Scale that consists of 16 items (Gilbert \& Allan, 1998). Example items are: 'I have the feeling that others don't respect me enough' and 'I feel that I am basically a winner' (reverse code). Items were assessed on a 5-point scale (i.e., $0=$ never to $4=$ always). Cronbach's alpha for this scale was 0.91 .

\subsection{Statistical analyses}

The Statistical Package for Social Sciences 22.0 (SPSS, Chicago, Illinois) was used for data analysis. The internal consistency of all validated scales and the new developed scales was computed using Cronbach's alpha. Because of the small sample size, and the explicit predictions, all tests were done one-tailed.

\section{Results}

\subsection{Structure of the OHIP-14.}

A factor analysis was conducted over all 14 items of the slightly adapted version of the Dutch OHIP-14, the results of which are presented in Table 1. The results showed three clear, theoretically and practically meaningful factors. The first factor had 5 items loading higher than 0.60 (e.g., painful aching in mouth, uncomfortable to eat any foods, problems with pronouncing any words), and one item with a loading of 0.56 (sense of taste has worsened). This factor can be labeled as functional limitations. A scale containing these 6 items $(\mathrm{Q} 2, \mathrm{Q} 3, \mathrm{Q} 4, \mathrm{Q} 5, \mathrm{Q} 10, \mathrm{Q} 14)$ had a coefficient alpha of 0.83 , which could not be raised by deleting an item.The second factor had 6 items loading higher than 0.60 (e.g., feeling a bit embarrassed and felt tense because of problems, life in general was less satisfying). This factor can be labeled as social discomfort. A scale containing these 6 items (Q7, Q8, Q9, Q11, Q12, Q13) had a 
coefficient alpha of 0.82 , which could not be raised by deleting an item. The third factor had two items $(\mathrm{Q} 1, \mathrm{Q} 6)$ loading higher than 0.70 , and all other items loading lower than 0.33 (i.e., self-conscious and totally unable to function). This factor can be labeled as psychological inhibitions (Q6 was reverse scored for the factor analysis). A scale was constructed by summing these two items without recoding, $r=0.40, p<$ 0.001 .

\subsection{Effects}

Effects of sense of defeat on oral health. The results further revealed that a sense of defeat wasassociated with less oral health self-care. That is, sense of defeat correlated negatively with tooth brushing after breakfast, $r=-0.31, p<0.05$, and with tooth brushing before going to sleep, $r=-0.27, p<0.05$. For the other three measures of tooth brushing, no significant correlations were found, all $r^{\prime} s<0.13$. There was also evidence for an association between sense of defeat and oral health impact. That is, sense of defeat correlated positively with social discomfort because of one's teeth, mouth, or dentures $(r=0.34, p<0.06)$, and negatively with self-perceived oral health, $r=-0.29, p<0.05$, but not with functional limitations, $r=-0.07$, $n s$ or psychological inhibitions, $r=0.07$, $n s$.

Effects of social status on oral health. There was also evidence that a low social status was associated with less oral health self-care. Social status correlated positively with tooth brushing before going to sleep, $r=0.32, p<0.05$, but not with any of the other moments of tooth brushing, all $r^{\prime} s<0.21$. Social status did correlate in a quite different way than sense of defeat with oral health impact. There was only a positive correlation with psychological inhibitions, $r=0.36, p<0.05$, but not with social discomfort, $r=-0.21, n s$, and neither with functional limitations, $r=-0.13$, ns. In addition, there was a positive correlation of social status with self-perceived oral health, $r=0.33, p<0.05$.

\section{Discussion}

The aim of the study was to examine how among Dutch male forensic psychiatric patients, subjective social status and sense of defeat were related to moments of tooth brushing, perceived oral health, and oral health-related quality of life. The present paper is unique in a number of respects. First, from the theory of involuntary submissive strategies (Allan \& Gilbert, 1995; Buunk \& Brenninkmeyer, 2000) variables related to oral health were examined in a special sample, i.e., Dutch forensic psychiatric patients. Second, three new, and practically as well as theoretically meaningful scales for oral health impact we constructed, based on a factor analysis of the Dutch Oral Health Impact Profile-14 (OHIP-14; Werkhoven et al, 2004), i.e., functional limitations, social discomfort, and psychological inhibitions. Third, findings showed that subjective social status and sense of defeat were in distinct ways associated with these dimensions. That is, the more one experienced a sense of defeat, the more social discomfort one felt because of one's teeth, mouth and denture. In contrast, the higher one's subjective social status, the more one admitted to have 
psychological inhibitions in relation to one's teeth, mouth and denture. Fourth, selfperceived oral health was in a theoretically meaningful way associated with both social status and sense of defeat: the lower one's sense of defeat, and the higher one's subjective social status, the better one perceived one's oral health. Finally, both sense of defeat and subjective social status were associated with the most important aspect of oral self-care: the higher one's sense of defeat, and the lower one's subjective social status, the less likely one engaged in tooth brushing before going to bed.

\section{Table 1. Factor analysis of the items for oral health-related quality of life}

\begin{tabular}{|c|c|c|c|}
\hline \multirow[t]{2}{*}{ Items OHIP-14 } & \multicolumn{3}{|c|}{ Factors } \\
\hline & $1^{\text {th }}$ & $2^{\text {nd }}$ & $3^{\text {rd }}$ \\
\hline $\begin{array}{c}\text { Q1. Have you been self-conscious because of your teeth, mouth, or } \\
\text { dentures? }\end{array}$ & .078 & 077 & .777 \\
\hline Q2. Have you had painful aching in your mouth? & .783 & .110 & .026 \\
\hline $\begin{array}{l}\text { Q3. Have you had difficulty doing your usual jobs because of problems } \\
\text { with your teeth, mouth, or dentures? }\end{array}$ & .754 & .331 & 131 \\
\hline $\begin{array}{l}\text { Q4. Have you had trouble pronouncing any words because of problems } \\
\text { with your teeth, mouth, or dentures? }\end{array}$ & .631 & .262 & .025 \\
\hline $\begin{array}{l}\text { Q5. Have you found it uncomfortable to eat any foods because of } \\
\text { problems with your teeth, mouth, or dentures? }\end{array}$ & .662 & .113 & .112 \\
\hline $\begin{array}{l}\text { Q6. Have you been totally unable to function because of problems with } \\
\text { your teeth, mouth, or dentures? }\end{array}$ & .175 & .066 & .801 \\
\hline $\begin{array}{l}\text { Q7. Have you been a bit irritable with other people because of problems } \\
\text { with your teeth, mouth, or dentures? }\end{array}$ & .236 & .827 & -.138 \\
\hline $\begin{array}{l}\text { Q8. Have you been a bit embarrassed because of problems with your } \\
\text { teeth, mouth, or dentures? }\end{array}$ & .420 & .632 & .330 \\
\hline $\begin{array}{l}\text { Q9. Have you felt tense because of problems with your teeth, mouth, or } \\
\text { dentures? }\end{array}$ & .332 & .745 & .023 \\
\hline $\begin{array}{l}\text { Q10. Have you had to interrupt meals because of problems with your } \\
\text { teeth, mouth, or dentures? }\end{array}$ & .787 & .156 & 103 \\
\hline $\begin{array}{l}\text { Q11. Have you felt that life in general was less satisfying because of } \\
\text { problems with your teeth, mouth, or dentures? }\end{array}$ & -.122 & .805 & .246 \\
\hline $\begin{array}{l}\text { Q12. Has your diet been unsatisfactory because of problems with your } \\
\text { teeth, mouth or dentures? }\end{array}$ & .428 & .601 & .255 \\
\hline $\begin{array}{l}\text { Q13. Have you found it difficult to relax because of problems with your } \\
\text { teeth, mouth, or dentures? }\end{array}$ & .387 & .675 & -.008 \\
\hline $\begin{array}{l}\text { Q14. Have you felt that your sense of taste has worsened because of } \\
\text { problems with your teeth, mouth, or dentures? }\end{array}$ & .564 & .197 & 156 \\
\hline
\end{tabular}

\subsection{Implications}

The present findings have a number of theoretical and practical implications. First, the finding that perceived oral health was higher with increasing subjective social status and decreasing sense of defeat is in line with research among young male criminal offenders that showed that life satisfaction was in the same way, and to the same degree (correlations around 0.30 ), associated with subjective social status and 
sense of defeat (Buunk, et al., 2016). Overall, these findings underline the theoretical relevance of the theory of involuntary subordinate strategies (Allan \& Gilbert, 1995; Buunk \& Brenninkmeyer, 2000) for the psychological situation of law offenders who are confined to criminal institutions. Second, monitoring patients' psychological and psychiatric state with special attention for feelings of low status and defeat may contribute to more adequate oral health related prevention and treatment. The findings suggest that paying attention to such feelings of the patient ('How do you feel about your situation?') may eventually result in taking better care of one's oral health by patients and consequently in less social discomfort because of one's oral health. In general, the present findings underline that the patients' psychological state (e.g., negative emotions and wellbeing) is related to one's perceived oral health and oral health related behavior such as tooth brushing. Acknowledging this is not only essential for a correct diagnosis and applying professional oral health care, but also within forensic health care to support patients' oral self-care by providing information on why and how to practice optimal oral self-care (Buunk-Werkhoven, Dijkstra-le Clercq, de Jong, \& Spreen, 2012). In the case of oral pathology, a patient should adapt his or her behavior by complying with a prescribed treatment or care, so called 'health deviation self-care', which may be carried out by mental health nurses in collaboration with dentists and oral hygienists (Dashiff, 1988; Denyes, Orem, \& Bekel, 2001; de Mey, Çömlekçi, de Reuver, van Waard, van Gool, Scheerman, \& van Meijel, 2016).

Of course, further research on this issue in other forensic institutes is essential, as this pilot study was restricted to male forensic psychiatric patients in one institution. More research is also needed on the association of subjective social status and sense of defeat with oral health related quality of life as measured in the present research, and with self-perceived oral health. It would be particularly important to assess these issues also in samples from the general population. Nevertheless, the present pilot study underlines that oral health professionals and other professionals working with male forensic psychiatric patients should be sensitive to the low status and sense of defeat these patients may experience, and to the fact that this may be associated with problems with their oral health (teeth, mouth and denture) and a lack of oral self-care.

\section{Acknowledgments}

We would like to thank Dr. Marius Spreen and Dr. Jose Heesink for their advice and support. Especially, thanks to the patients for taking part in this study.

Both authors declare that they have no conflict of interests.

\section{References}

[1] Allan, S., \& Gilbert, P. (1995). A social comparison scale: Psychometric properties and relationship to psychopathology. Personality and Individual Differences, 19, 293-299. 
[2] Barkow, J.H. (1989). Darwin, sex, and status. Biological approaches to mind and culture. Toronto: University of Toronto Press.

[3] Brein, D.J., Fleenor, T.J. Jr., Kim, S.W., \& Krupat, E. (2016). Using the Theory of Planned Behavior to identify predictors of oral hygiene:A collection of unique behaviors. Journal of Periodontology, 87, 12-9.

[4] Buunk, A.P., \& Ybema, J.F. (1997). Social comparisons and occupational stress: the identifaction-contrast model.In Buunk A.P., Gibbons F.X. (Eds.), Health, coping and well-being: Perspectives from social comparison theory. (pp. 359388). Hillsdale, NJ: Erlbaum.

[5] Buunk, A.P., \& Brenninkmeyer, V.B. (2000). Social comparison processes among depressed individuals: Evidence for the evolutionary perspective on involuntary subordinate strategies? In L. Sloman and P. Gilbert (Eds.), Subordination and defeat: An evolutionary approach to mooddisorders (pp. 147-164). Mahwah: Lawrence Erlbaum Associates Publishers.

[6] Buunk, A.P., Peíró, J.M., Rodríguez, I., \& Bravo, J.M. (2007). A loss of status and a sense of defeat: An evolutionary perspective on professional burnout. European Journal of Personality, 21, 471-485.

[7] Buunk, A.P., Peiró, J.M., Rocabert, E., \& Dijkstra, P. (2016). Life satisfaction and status among adolescent law offenders. Criminal Behaviour and Mental Health, 26, 94-100.

[8] Buunk-Werkhoven, Y.A.B.., Dijkstra, A., van der Wal, H., Basic, N., Loomans, S.A., van der Schans, C.P. \& van der Meer, R. (2009a). Promoting oral hygiene behavior in recruits in the Dutch army. Military Medicine, 174, 971-976.

[9] Buunk-Werkhoven, Y.A.B., Dijkstra, A., \& van der Schans, C.P. (2009b). Oral health-quality of life predictors depend on population. Applied Research of Quality of Life, 4, 283-293.

[10] Buunk-Werkhoven, Y.A.B., Dijkstra, A., Schaub, R.M.H., van der Schans, C.P., \& Spreen, M. (2010). Oral health-related quality of life among imprisoned Dutch forensic psychiatric patients. Journal of Forensic Nursing, 6, 137-143.

[11] Buunk-Werkhoven, Y.A.B., Dijkstra, A., \& van der Schans, C.P. (2011a). Determinants of oral hygiene behavior: a study based on the theory of planned behavior. Community Dental and Oral Epidemiology, 3, 250-9.

[12] Buunk-Werkhoven, Y.A.B., Verheggen-Udding, E.L., Van den Heuvel, J.L.M. (2011b). Mondgezondheid gerelateerde levenskwaliteit bij patiënten met terbeschikkingstelling. [Oral health related quality of life among Dutch forensic psychiatric patients]. Nederlands Tijdschrift voor Tandheelkunde, 118, 273-5. 
[13] Buunk-Werkhoven, Y.A.B., Dijkstra-le Clercq, M., de Jong, N., \& Spreen, M. (2012). Halitosis and oral health-related quality of life: A case report. International Journal of Dental Hygiene, 10, 3-8.

[14] Campbell, A. (2002). A mind of her own: The evolutionary psychology of women. Oxford University Press.

[15] Cantril, H. (1965). The pattern of human concerns. New Brunswick, NJ: Rutgers University Press.

[16] Cummins, D. (2005). Dominance, status, and social hierarchies. In: D.M. Buss (Ed.). The handbook of evolutionary psychology (pp. 676-697). Hoboken, NJ: John Wiley and Sons.

[17] Dashiff, C.J. (1988). Theory development in psychiatric-mental health nursing: An analysis of Orem's theory. Archive Psychiatric Nursing, 2, 366-372.

[18] de Mey, L., Çömlekçi, C., de Reuver, F., van Waard, I., van Gool, R., Scheerman, J.F., \& van Meijel, B. (2016). Oral hygiene in patients with severe mental illness: A pilot study on the collaboration between oral hygienists and mental health nurses. Perspective in Psychiatric Care, 52, 194-200.

[19] Denyes, M.J., Orem, D.E., \& Bekel, G. (2001). Self-care: A foundational science. Nursing Science Quarterly, 14, 48-54.

[20] Gilbert, P., \& Allan, S. (1998). The role of defeat and entrapment (arrested flight) in depression: An exploration of an evolutionary view. Psychological Medicine: A Journal of Research in Psychiatry and the Allied Sciences, 28, 585598.

[21] Glick, M., Williams, D.M., Kleinman, D.V., Vujicic, M., Watt, R.G., \& Weyant, R.J. (2016). A new definition for oral health developed by the FDI World Dental Federation opens the door to a universal definition of oral health. Journal of American Dental Association, 147, 915-917.

[22] Locker, D. (1988). Measuring oral health: A conceptual framework. Community Dental Health, 5, 3-18.

[23] Patel, J., Kulkarni, S., Doshi, D., Reddy, S., Reddy, P., \& Buunk-Werkhoven , Y.A.B. (in press). Determinants of Oral Hygiene Behavior among moderate and severe chronic periodontitis patients based on the Theory of Planned Behavior. International Dental Journal.

[24] Werkhoven, Y.A.B., Spreen, M., Buunk, A.P., \& Schaub, R.M.H. (2004). Mondzorg in de Dr. S. van Mesdagkliniek heeft meer om het lijf. [Oral health care in Dr. S. van Mesdag Forensic Psychiatric Centre: More than oral health care alone]. GGzet Wetenschappelijk, 8, 36-40. 